\title{
Mathematical Reasoning Analysis in Solving Limit Functions Problems of Students in Mathematics Education of Pare-pare Muhammadiyah University
}

\author{
Asdar Dollo \\ Mathematic Education \\ University of Muhammadiyah ParePare \\ Indonesia \\ asdardollo@ymail.com
}

\begin{abstract}
This research aimed to describe the students' reason in solving the problem of limit function and comparation between high-ability subject (HS) and medium-ability subject (MS). The instrument in this research was the researcher himself as the main instrument guided by the task limit function and valid interview guidelines. Data collection was done by taskbased interviews. The subjects of the study were $\mathrm{V}$-semester students consisting of 2 students ( 1 subject is having high ability and 1 subject is having medium ability). The research process followed the steps of: (a) formulating the mathematical reasoning indicator in solving the problem of limit function based on theory, (b) formulating the supporting instrument (task limit function and interviewing guide), (c) taking the research subject, (d) taking the data to tell the students' reasoning in solving the limit function tests (f) conducting analysis of mathematical reasoning data of the students in solving the problem of function limit, (g) conducting discussion of analysis result, (h) concluding the research results. The result of the research showed that 1) the reasoning equation of the high-ability subject (HS) and the medium ability subject (MS) in solving the function limit problem was to do inductive reasoning first then perform deductive reasoning, 2) difference of reasoning subject with high ability (HS) medium ability (MS) in solving the problem of function limit was only in terms of mathematical reasoning process.

Keywords : mathematical reasoning; high ability subject; medium ability subject
\end{abstract}

\section{INTRODUCTION}

The most important basic lessons learned by the student from the basic to the top level are math. The function and role of mathematics is enormous in many disciplines because mathematics is a universal science and plays a major role in the development of Science, Technology, and the Arts (IPTEKS).

Mathematics is a necessary knowledge of students to support their learning success for higher education. Mathematics is also a means of scientific thinking necessary to develop logical, systematic and critical thinking skills of students, even in everyday life it is not be separated from the use of mathematics itself, albeit in its simplest form. 
According to Shurter and Pierce (Sumarmo, 2010) reasoning is one of the basic competencies of mathematics in addition to understanding, communication and problem solving. Reasoning is also a process of thinking in developing the mind of some facts. Mathematical reasoning required students both in the process of understanding mathematics as well as in everyday life. In learning mathematics, reasoning ability plays an important role, for example when solving problems in the private sphere, society and other social institutions more broadly.

Many problems faced in the world of education, especially mathematics education shows that the ability of students' mathematical reasoning is still very weak. The results of previous researches have shown the low level of math skills of students in schools, as did (Ruseffendi, 1991) suggesting that there are many children after studying math, even the simplest parts of it, many of them do not understand, even many concepts are misunderstood. Mathematics is considered to be a difficult, intricate and deceptive science. This proves that many children have difficulty in learning mathematics, because most of them do not understand the concept but memorize it.

The results of other researchers conducted by Wahyudin (1999), in detail found that one of the tendencies that led to a number of learners failed to master it well of the mathematics subjects was the lack of understanding and the use of good reason in solving problems or given problems.

One of the materials considered difficult by the students of Mathematics Education Study Program of Pare-pare Muhammadiyah University was function limit material. Many students have difficulties in solving problems concerning material function limits. The difficulty in question was the frequency of students making mistakes in solving problems. Whether principle errors such as misleading the limit theorem function, the nature of function limits, as well as procedural errors such as sleeplessness and the inability to manipulate steps. In solving the problem of function limit, the students cannot give the right answer. Whereas, one of the important skills that are expected to be mastered by students is the ability to solve math problems appropriately.

Information obtained from some students in the Mathematics Education Study Program of Pare-pare Muhammadiyah University who have studied the material function limit indicated that many students found difficulties in solving the problem of function limit, so they were not able to solve the problems properly. This was in line with information from lecturers who teach the material. He said that in a class, most of the students were not able to solve the problem of function limit especially the function limit properly. This illustrated that the mathematical reasoning ability of the students of Mathematics Education Study Program of Parepare Muhammadiyah University was generally still low.

Based on the above description, it was necessary to know how the description of the students' reasoning of Mathematics Education Study Program of Parepare Muhammadiyah University in solving the problem of function limit. Knowledge of the students' reasoning description of Mathematics Study Program of Parepare Muhammadiyah University in solving the problem of function limit could help the lecturer 
to reflect the learning of the limit concept so that the students have an understanding in accordance with the concept of the function limit and able to solve the problem of function limit properly. This was what encouraged researchers to raise the issue with the title "Analysis of Mathematical Reasoning in Solving Function Limit Problems In Mathematics Education Students of Parepare Muhammadiyah University". The purpose of this research was to describe the reasoning of mathematics students of Mathematics Education Study Program of Parepare Muhammadiyah University in solving the problem of function limit.

Mathematical reasoning that included the ability to think logically and systematically was the highest cognitive domain of mathematics. Dirjen Dikdasmen's regulation no. 506 / C / PP / 2004 (Marpiyanti, 2012) is about reasoning and communication indicators to be achieved by learners. Indicators that demonstrated reasoning and mathematical communication included:

1. The ability to present math statements orally, in writing, drawings, and diagrams

2. The ability to file allegations

3. The ability to manipulate

4. The ability to compile evidence and provide reasons for the correctness of the solution

5. The ability to draw conclusions from statements

6. Checking the validity of an argument

7. Finding the pattern or nature of mathematical phenomena to make generalizations

Reasoning associated with problem solving were two things that cannot be separated. This was because when students looked for solutions to a problem then the students performed the process of conscious activity in seeking solutions of mathematical problems given through a mental activity called reasoning. Every step of the problem solving, students did reasoning activity. So it could be drawn a conclusion that the solution of mathematical problems was closely related to mathematical problems because in solving mathematical problems, it was needed mathematical reasoning. In general, there were two types of reasoning, namely (1) inductive reasoning and (2) deductive reasoning.

\section{1) Mathematical Problem Solving}

Ruseffendi (Alhadad, 2011) argues that a problem is a problem for a person, first if the problem is unknown or in other words the person does not have a specific procedure or algorithm to solve it. Hudoyo (Ibrahim, 2011), divides problems in mathematics into six types, namely: routine, non-routine, routine-applied, non-applied routine, and non-routine non-applied.

Some opinions above can be concluded that the problem of mathematics is a matter that cannot be searched solution or answer directly, but require deep thinking.

\section{2) Student Reasoning Indicators in Solving Function Limit Problems}

Mathematical reasoning in this research was a mental activity in solving problems that included: (1) Presenting mathematical statements in writing or oral; (2) Filing allegations; (3) Conducting mathematical manipulation; (4) Developing evidence or solutions and giving reasons for the correctness of the solution; (5) Drawing conclusions; and (6) Examining the validity of an argument. 


\section{RESEARCH METHODS}

The type of this research was a qualitative descriptive research that aimed to describe the process of students' mathematical reasoning in solving the problem of function limit. This research was conducted in Mathematics Education Study Program of Parepare Muhammadiyah University. Subjects of this research were the students of semester V of Mathematics Education Study Program at Parepare Muhammadiyah University in academic year 2017/2018 who has studied function limits of Calculus I. The chosen subjects were 2 students, consisting of 1 high ability student (HS) and 1 medium ability student (MS) with consideration of GPA and communication skills.

\section{RESEARCH RESULT AND DISCUSSION}

This research was a qualitative research, which illustrated the selected research subject naturally, in this case was a high ability subject (HS) and a medium ability subject (MS) to uncover students' reasoning in solving the problem of function limits.

The valid data of a high ability subject (HS) in solving the functionality limit problem was as follows:

\section{1) Understand the problem}

a) High ability subject written or expressed mathematical statements in explaining the problem again

b) High ability subject estimated the answers as well as the settlement steps that will be done.

2) Plan the completion

a) High ability subject planned to apply L'Hospital's theorem

3) Undertake a plan of completion

a) High ability subject to write or express mathematical statements in preparing solutions.

b) High ability subject performed mathematical manipulation by differentiating the numerator and its denominator.

c) High ability subject developed solutions or solutions by using L'Hospital's theorem, and the nature of function limits and provided reasons for taking such steps.

d) High ability subject drawn conclusions based on logical steps that have been taken earlier in solving the problem of function limits.

4) Checking back

a) A high ability subject examined the validity of the argument in every step of the solution that he does with no clawing, so he only did in his thinking activity. 
The valid data of moderate-capable subjects (MS) in solving the functionality limit problem are as follows:

\section{1) Understand the problem}

a) High ability subject wrote or expressed mathematical statements in explaining the problem again

b) High ability subject estimated the completion steps that will be done.

2) Plan the completion

a) High ability subject planned to rationalize the denominator first

3) Undertake a plan of completion

a) High ability subject to write or express mathematical statements in preparing solutions.

b) High ability subject perform mathematical manipulation by multiplying the numerator and the denominator with the roots of the denominator.

c) High capable subject developed solutions or solutions by rationalizing the denominator, and using the features of functional limits as well as providing the reasons for taking such steps.

d) High ability subject drew conclusions based on logical steps that have been taken earlier in solving the problem of function limits.

4) Checking back

a) A high ability subject examined the validity of the argument in every step of the solution by scratching or scribbling.

High ability subjects (HS) and medium ability subjects (MS) were equally inductive reasoning first by analogies or generalizations and then performed deductive reasoning in solving the function limit problem. The difference in mathematical reasoning of a high ability subject (HS) and a medium ability subject were in the process of reasoning. In submitting a presumption, a high ability subject (HS) estimates the answers or steps to be taken, while the medium subject (MS) only estimated the steps of completion. In performing mathematical manipulation, the subject of high ability (HS) differentiates (decreases) the numerator and its denominator, while the moderate subject (MS) multiplies the numerator and its denominator with the roots of its denominator. In preparing the solution, the high-ability subject (HS) used L'Hospital's theorem, while the moderate subject (MS) rationalized the denominator. In examining the validity of an argument, medium-tempered subjects (S) did so by scratching or scribbling, while the high-storied subject (HS) did so without scratching or scribbling.

High ability subjects were able to properly resolve the problem of function limits. While the medium ability subject (MS) was not able to solve the problem of limit function properly. The medium ability subjects were less careful and wrong in solving the problem. Medium ability subjects were wrong in doing mathematical manipulation or in preparing solutions. 


\section{CONCLUSION}

High ability subject Reasoning (HS) in Solving Limit Functionality Issues, namely:

1) Understanding the problem, namely: to present mathematical statement in writing or oral in explaining the purpose of the problem and to propose the estimation of the answer or step to be done.

2) Planning the settlement, ie: plan to use L'Hospital's theorem.

3) Making a plan of completion, ie: performing mathematical manipulations by differentiating (dividing) the numerator and denominator, preparing the solution with L'Hospital's Theorem and the limit properties of functions and drawing a conclusion.

4) Checking again, ie checking the validity of an argument in its thinking activity, without clawing or scribbling.

a) Medium Subject Reasoning (MS) in Solving Limit Functionality Issues, namely:

(1) Understanding the problem, namely: to present mathematical statement in writing or orally in explaining the purpose of the problem and to propose the estimation of the steps to be performed.

(2) Planning the settlement, ie plan to rationalize the denominator

(3) Making a plan of completion, namely: performing mathematical manipulation with the numerator and denominator with the roots of the denominator, compile the solution by rationalizing the denominator and the properties of the function limit and drawing a conclusion.

(4) Checking again, ie check the validity of an argument by scratching or doodling.

b) Equation of High Ability Subject of Mathematics Reasoning (HS) with Medium Ability Subject (MS) in solving Limit Function Problems, High Ability Subjects (HS) and Medium Ability subjects (MS) were both inductive reasoning and then deductive reasoning. While the difference in the reasoning of High Ability Subject of Mathematics (HS) with Medium Ability Subject (MS) in Solving Limit Function Problems, which was in the process of reasoning, especially in performing mathematical manipulation, making solutions and checking the validity of an argument.

\section{REFERENCES}

Sumarmo, Utari. Mathematical Thinking and Disposition: What, Why, and How Developed in Learners. (Online), (2010). (http://math.sps.upi.edu/wpcontent/upload /2010/02/berpikir-dan-disposisi-matematik-SPS-2010. Pdf, accessed on 22 January 2017)

Ruseffendi, E.T. (1991). Introduction To Helping Teachers Develop Their Competencies in Mathematics Teaching to Improve CBSA. Bandung: Tarsito

Wahyudin. (1999). Ability of Math Teachers, Math Teacher Candidates, and Students in Mathematics Subjects. Doctor's Disappointment at FPS UPI Bandung: Unpublished 
Marpiyanti. (2012) Improvement of Understanding Concept And Mathematical Reasoning Through Problem Based Learning In Student Class XI IPA SMA Topoyo. Thesis Not Published. Makassar: UNM Postgraduate Program.

Alhadad, Syarifah Fadillah. (2011). Improve Multiple Mathematical Representation Ability, Mathematical Problem Solving, And Self Esteem Smp Students Through Learning With Open Ended Approach. Dissertation. Repository.upi.edu

Ibrahim. (2011). Improved Communication Skills, Reasoning, and Mathematical Problem Solving And Emotional Intelligence Through Problem-Based Learning at High School Students. Dissertation. Repository.upi.edu 